'Choreography, Controversy and Child Sex Abuse: theoretical reflections on a cultural criminological analysis of dance in a pop music video'

Melissa Dearey

Abstract: This paper was inspired by the controversy over claims of 'pedophilia!!!!' undertones and the 'triggering' of memories of childhood sexual abuse in some viewers by the dance performance featured in the music video for Sia's 'Elastic Heart' (2015). The case is presented for acknowledging the hidden and/or overlooked presence of dance in social scientific theory and cultural studies and how these can enhance and advance cultural criminological research. Examples of how these insights have been used within other disciplinary frameworks to analyse and address child sex crime and sexual trauma provided, and the argument is made that popular cultural texts such as dance in pop music videos should be regarded as significant in analysing and tracing public perceptions and epistemologies of crimes such as child sex abuse.

Key words: dance; choreography; child sexual abuse; music video; kinaesthetic; cultural criminology

The representation of crime narratives in popular cultural forms as sources for entertainment is ethically deeply fraught (Leszkiewicz, 2016). Adorno's famous dictum concerning the barbarism of poetry after Auschwitz illustrates the difficulties of using survivor testimony and/or trauma linked to atrocity level crime and suffering for the purposes of art or entertainment; yet it remains that among the most moving, revealing and politically challenging expressions of experiences of atrocity have been those rendered in popular art forms such as posters, short animated films and cartoon strips (Copley, 2010), and also, in more recent years, in popular music and video (e.g. Martin, 1998). These texts stand as testaments to the endurance, credibility and legitimacy memory and the diversity, challenges, and innovation of human creativity, often eliciting nuanced and complex responses from mass audiences, some of whom have suffered similar trauma. Some members of these mass audiences have had their own memories and experiences of abuse denied, dismissed, or repressed; for some, memories, feelings or experiences are reinvigorated or 'triggered' by what they have seen or 'consumed' in popular cultural media. Others who have not experienced such trauma, or have not had it 'triggered' by such texts, nevertheless also express confusion or concern about the meanings of these texts, and indeed about the role of popular culture and the right or ethics of artists to express themselves in a manner that elicits such controversy and pain. These issues have been raised recently in the social media controversy that has surrounding the dance performance by a then eleven year old girl (Madeleine Ziegler) and an older man (Shia Leboeuf) featured in Sia's pop music video for 'Elastic Heart' (2015). As a criminologist interested in the representation and public epistemologies of crime in popular media and art, and also as a dancer myself interested in dance and movement theory, I was immediately curious about this controversy and what it 
might reveal about public and institutional perceptions of a crime like child sex abuse, and what dance could offer for criminological theory and analysis.

Utilising interdisciplinary methodologies developed within dance and movement studies (e.g. Adshead (latterly Adshead-Lansdale), 1986a, 1986b, 1988, 1999) and cultural criminology (Ferrell and Sanders, 1995; Ferrell et al, 2008; Ferrell, 2004; Presdee, 2000), this paper presents an interdisciplinary analysis of this controversial dance performance in the pop music video genre and audience reactions to it with respect to its putatively 'paedophilic' overtones. At the centre of this analysis is a recognition —and insistence — of the seminal importance of the dancing body as a moving, emotional, and visceral presence in this type of crime and victimisation and public notions of it, and the need for the integration into criminology of interdisciplinary methodologies focused on choreography and expressive, emotional, visceral and moving bodies in relationship to each other. This theoretical approach recognises and prioritises the role of the body as a reliquary of memories of trauma and abuse in real and imagined time and space, and the role of the arts to express and archive these memories and experiences, as conceptualised within dance and by dance and movement studies. It is suggested that this provides another avenue for understanding the cultural construction of crimes that elicit high levels of public opprobrium and moral panic, and hence are especially difficult to discuss, such as child sex abuse, and their representation and memorialisation in and through dance performance and popular culture. Broader methodological and theoretical commentary linking criminology as a social science discipline with dance and movement studies will be provided by way of justification and background for readers who may be unfamiliar with dance and movement studies, and its historical links with social science theory.

First I will briefly turn my attention to defining cultural criminology with respect to what it is and how it has been received:

Cultural criminology is a distinct theoretical, methodological, and interventionist approach to the study of crime that places criminality and its control squarely in the context of culture; that is, it views crime and the agencies and institutions of crime control as cultural products or as creative constructs. As such they must be read in terms of the meanings they carry. The focus of the field is broad, comprising situated and symbolic meaning; constructed social identity; subcultural analysis; space, place, and cultural geography; the ongoing transformations and fluctuations associated with hypercapitalism; vicissitudes of power, resistance, and state control; and existentialism and concepts of risk, 'edgework,' and embodied practice. In all this, cultural criminology attempts to reorient criminology to contemporary social and cultural changes and thus to imagine a 'postmodern' or 'late modern' theory of crime and control. In this regard cultural criminology is interested in how individuals strive to resolve certain internal psychic and emotional conflicts that are themselves spawned by the contradictions and peculiarities of contemporary life. Put differently, cultural criminology seeks to fuse 'a phenomenology of contemporary transgression with a sociocultural analysis of late modern culture' (Hayward 2011: 9). 
Cultural criminology has itself proven controversial, with commentators such as Spencer (2010) contesting its ontological and epistemological credibility and criticising it for its lack of conceptual vocabulary or theoretical distinctiveness, arguing that it offers little if anything that is 'new' let alone 'inviting', being in essence a re-invention of labelling theory. While this paper is not about the debate over the theoretical viability of cultural criminology or its distinctiveness or otherwise from other theories of deviance developed in the 1960s and 1970s, it does embrace what Spencer castigates if for over its theoretical texture which he likens to 'soup' (Spencer, 2010: 198). While soup may not be palatable to some, it is nevertheless considered delicious and nutritious by others. It is a cookery form that has been used by peasants as well as Michelin starred chefs to make the most out of what are often viewed as meagre, low value, uninspiring or not particularly appetising ingredients to make something that can be surprisingly tasty, comforting and extremely nourishing.

To extend this metaphor, there is arguably what could be called a 'soupiness' to the story behind the inspiration, creation and production of the dance performed in 'Elastic Heart' as described by its choreographer Ryan Heffington in collaboration with Sia, the then eleven year old dancer Madeleine Ziegler, and the video's co-director Daniel Askill in their response to the controversy that erupted upon release of the music video. In their subsequent video rebuttal entitled 'The Story behind Sia’s Elastic Heart Video!' (Danceon, 2015), they describe a recipe of eclectic ingredients for this choreography and dance performance that includes among its ingredients David Lynch, a dancing wolf, warring self states, a levitating banana mask, a skull cage, Dance Moms and a smelly Shia Leboeuf collectively as the basis of the narrative stew that is this dance. Served up to dismiss or deflect accusations of paedophilic content of the dance, it does not mention or directly address the 'triggering' controversy (see Good, 2015; Grow, 2015). Judging by the popularity and critical acclaim for this performance, the palatability of this concoction is high; however the credibility of such explanations over its real meaning by its creators to divest it of its more controversial 'paedophilic' overtones is debatable. While not dismissing their own accounts of the creative process behind the choreographing, casting and performance of this dance, as is the case with all forms of art, popular or elite, it is not in the power of creators or artists to determine the meaning of what they produce, just as much as it is not in the gift of cooks to decide whether or not their food is good, the proof of the pudding being famously in the eating, not (just) the making.

Drawing upon reader response theory, Vernallis (2004) argues that it is one thing for an artist to claim make decisions about what goes into a music video and the intended meanings, but it is for audiences to decide how much these reflect the performers' own feelings, and what the resulting meanings actually are. Meanings in relation to bodies in terms of their movements, deportment and costuming are particularly important in the cultural receptions of dance music videos. Dance in music video is there in order to '...instruct us how we should feel about our bodies within a certain cultural epoch. Certainly the small, fluid gestures - the "jerk, jerk, jerk"--and arms spread wide of today [2000s] is different from the sinuous S-curves of the early 1990s and the broader, wooden, robotic movements of the early 1980s' (Vernallis, 2004: 71). From this perspective, audience interpretations of the choreographic movements 
contained in 'Elastic Heart' are as legitimate, meaningful and 'truthful' as those intended by the artists, if not more so, regardless of the intention of the artists; such meanings of art, even popular art, cannot be circumscribed, controlled or denied. It is the meanings that have been attached to this dance performance, and the feelings and questions that have been raised by it that are also elemental to what it is, as a work of art, and also as a source of analysis for art and cultural theorists, including criminologists. So in that respect, the subject matter is consistent with cultural criminological theory, not least in its soupiness.

Dance and the social sciences - civil society, trauma, memory and movement

What is dance, this most fragile, ephemeral and also popular and participative art form (Bresnahan, 2015), how is it to be interpreted, and what does it offer theoretically and methodologically as somatic and embodied practice in space and time? As the dance scholar Janet Adshead/Adshead-Lansdale (1986a, 1986b, 1988, 1999) posits, intertextuality is essential to the analysis and interpretation of dance and the exploration its meanings, hence the appropriateness of poststructuralist methodologies and their application to other interdisciplinary research and other contexts, such as crime and victimisation. Among the essential components of dance analysis she identifies is the costuming and presentation of the body/ies, determination of genre codes and hence identification of conventions of movements and their meanings, biographical details of dancers and choreographers, cultural and historical settings of dance spaces, purpose of the dance (e.g. entertainment, art), 'effortshape' of movements, staging (Adshead, 1988) and finally the semiotics of movement (Adshead-Lansdale, 1999), all of which are explored in more detail in my accompanying analysis of this dance in a separate paper (Author 2018). The primary aim here is to establish the theoretical justification for such an interdisciplinary integration between (cultural) criminology and dance and movement studies, and to encourage criminologists to attend more directly to the choreographic analyses, expression, and public consumption of crime, so my references to these elements will be by necessity brief.

In her extensive and landmark writing on dance analysis, theory and practice (1986a, 1986b, 1988, 1999), Janet Adshead-Lansdale maps the emergence of dance research over the last twenty or thirty years, tracing its evolution from the multidisciplinary fields of anthropology, history, psychology, sociology, and theology. While the interdisciplinary convergence of dance with criminology might at first appear odd, dance as a mechanism for expressing modes of deviance and resistance for a variety of subcultural groups is strongly evidenced, as is its use as a mechanism for human rights abuse and social control (see Jackson and ShapiroPhim, 2008). Historically dance has been seriously neglected within academia, including in the arts, aesthetics (Bresnahan, 2015) and in the sociology of art and cultural studies (Thomas, 1995) - in favour of a concentration on the so-called visual arts, as if dance was not fundamentally 'visual'. As Bresnahan (2015) explains, this is in many ways an extension of early and high modern philosophical traditions, notably Hegelian idealism, that prioritised and categorised the fine arts as 'fine' due to their essential link to the 'idea' and its manifestation in an art work as a creative, artistic and spiritual expression of 'truth'. As with Cartesian rationalism, this resulted an attitude to the arts that derided, neglected or left unchallenged the notion that truth did not or only tangentially involved the body, emotions or 
the experiences of ordinary life in favour of the realisation of knowledge as phenomenal of 'consciousness'.

This contrasts to other philosophical approaches to subjectivity and the arts which were more emphatic in their defence of dance and indeed it complex but vital relationship to knowledge, understanding and reason. Thinkers and writers as diverse as Plato, Nietzsche and Walt Whitman overtly acknowledged the irrepressible lure to move, to move freely, and to move to music, and how dance codifies and presents a mode of liberation, ebullience and joy that actually enables and facilitates the phenomenon of human understanding through lived and intrinsically conceptual as well as corporeal experiences of harmony, beauty, learning, endurance, growth and change. Dance thus invigorates a lightness of spirit and intellectual irreverence characteristic of iconic figures of modern thought such as Nietzsche's Zarathustra, who while he pronounced the death of God, nevertheless conceded 'I would only believe in a God who could dance' (Nietzsche, 1969; Monasterio, 2015). Adorno took this further in his focus upon the ephemeral character of dance as an antidote and active affront to a '...strategy of hypostasis' that ranks as 'one of the most objectionable features of traditional philosophy' with its 'preoccupation with "permanent, unchanging essences", and accordingly its bent to hypostasize historical experiences into timeless truths' (Dallmayr and Adorno quoted in Harding, 1997: 165).

In the social sciences, dance features in some of its most canonical theories and works, though this is often overlooked or forgotten. In the nineteenth and early twentieth centuries, social scientists such as Emile Durkheim (2008) were cognisant of the ritualistic and symbolic importance of dance within communities and belief systems, particularly during tumultuous times and periods of conflict. Karl Marx highlighted the significance of cultural forms as super structural manifestations of historical material shifts and contradictions in economic means of production, and indeed there is evidence that the arts, and dance and movement specifically, were influential in Marx’s life and works (Riff, 2015). Max Weber (Gerth and Mills, 2009) also recognised the importance of music and dance in a variety of ideological and sociological contexts and their role as emblems of class identities, hierarchies of power and modes of experiencing magic and the sacred. Norbert Elias's seminal thesis presented in The Civilising Process (2000) was rooted in a keen awareness of the semiotics of the body and its intricately choreographed deportment in daily life as pivotal to the very notions of civility and barbarity formative to modernity, comprising a transformative historical process that took place through affective changes and manifest in distinctively corporeal and performative 'signals', such as of delicacy, repugnance or shame:

Through a careful survey of etiquette books and other documents dealing with topics like table manners, blowing one's nose, spitting, the deportment of the body, facial expressions, and the control of bodily functions, Elias argues that Westerners went through a gradual and uneven affective transformation during the sixteenth and seventeenth centuries. By the end of the process, behaviours considered normal in the Middle Ages had been ruled 'barbarous,' and the civilized separation from barbarity signalled major changes in feelings of delicacy, shame, refinement, and repugnance (Leithart, 2011: online). 
In dance and movement studies, scholars have drawn on such philosophical and social scientific classics to inform their analyses, as for example in Hammond and Hammond's (1979) Weberian analysis of the history of ballet and the 'rationalisation' of the 'spirit' of modernity through physical carriage, expression and movement, and how these can reveal deeper meanings of power and identity symbolically encoded in dance.

Movement, deportment, and bodies in or out of contact and their associated semiotics and meanings are intrinsic to dance, and dance is intrinsically social (Thomas, 1995). But what is it, and why has it been so overlooked, even among the arts? Dance scholars have pondered the fundamental question 'what is dance?'. Traditionally, dance critics have adopted narrowly rigid definitions confined to deliberate and usually elite artistic expression conforming to disciplined and technical genre typologies, such as ballet, jazz, tap, Bharatanatyam, ballroom and Latin dance, which are regulated by international governing bodies. Other dance styles such as modern, lyrical, Bollywood and 'street' dance tend to be less rigorously or formally codified and regulated and are characterised by being more inclusive of the sorts of quotidian and commonplace bodily movements and their socio-cultural meanings within the domain of daily social life as enunciated by Elias above (Martin, 1998). Aili Bresnahan (2015) traces some of the debates surrounding efforts to define dance, including claims that dance movements are, or are not, 'actions' or indeed movements; and this is aside from the considerable problems she catalogues of writing about dance. Bojana Cvejic summarises the categories in European modern dance pithily as non-dance, anti-dance, 'conspicuously' conceptual dance, and 'dancey dance' (Cvejic, 2015). But even these categories are unstable and shifting, as many of the canonical moves of the most elite ballet corpus will include movements choreographed for and identifiable as those commonly found in ordinary motions of everyday life, and carry their (non-)dancerly connotations; dancers also innovate and add to their choreographic language by integrating movements from other types of dance, a phenomenon known broadly as 'fusion', a process of cross-pollination that often gives birth to new dance styles. As Thomas (1995) declares, whatever dance is, it is highly socially and culturally constructed, and consequentially changes over time, as do its meanings. In recent times, dance historians and scholars have noted the continuing erosion of conventions and boundaries separating what is usually understood as dance from the movement vocabularies of everyday life and ordinary life and task like actions, identifying this as what makes modern choreography generically distinctive and modern dance uniquely 'modern' (Adshead, 1986b). What is common to all is a concern with how bodies in motion are used to construct and convey meaning and emotion, in time and space, and how these movements and interactions can themselves be analysed to interpret and understand a broad if not comprehensive range of human phenomena expressed and/or experienced in and through dance, including those related to crime, victimisation, transgression, deviance, justice and punishment (see Armstrong, 2015). These latter pertain specifically to choreographic performances staged in a manner that elicit disgust, outrage, abjection, trauma, shame, and distress, mobilising the body as a grotesque, caged space for suffering, such as for example expressed in Japanese Butoh dance (Fraleigh, 1999).

Dance, movement, criminology and crime 
From the era of the Chicago School in the 1930s, criminology has a long established awareness of the significance of place and space, yet even within the relatively new domain of cultural criminology, there has been relatively little attention paid to how the choreographic and kinaesthetic interactions of moving and somatic bodies animate and occupy these places and spaces from a dance and movement based perspective, and how these patterns and meanings impact our understandings of crime, deviance, social control and harm. This situation is changing, with an awareness of the fundamentally performative and choreographic elements of crime and victimisation, such as in Elaine Campbell's recent analyses of the choreographies of policing (2016) and stalking (2012). Her work on choreography and crime however remains a relatively rare example in recent criminological research. Others such as those in dance, theatre and performance studies have signalled the way for criminologists, as for example Ananda Breed's (2014) documentation of the substantial role of dance and theatre in the gacaca court in post-genocide Rwanda in shaping notions of law, justice, ethnicity, nationhood, reconciliation and memorialisation. Researchers in multimedia, computer science and artificial intelligence such as Jansohn et al (2009) have utilized choreography for the development of digital technologies that enable police to detect pornographic and/or indecent images in large datasets of video material by focusing on movement patterns rather than static images. Hard science and social science disciplines such as law, politics, sociology, psychology and the neurosciences have also begun to avail of the insights offered by dance and movement studies. In his book Critical Moves: Dance Studies in Theory and Politics (1998), sociologist and dancer Randy Martin utilises dance theory to explore what are conventional criminological topics such as politics, gender, policing, violence and 'race' to interrogate how these constellated phenomena are shaped and influenced by and within popular culture, in this example though his analysis of dance in a hip hop music video by the artist Ice Cube. In a more empirical context, recent research in conflict and trauma studies undertaken collectively by legal scholars, neurobiologists and psychologists (e.g. Beausoleil and LeBaron, 2013; LeBaron and Alexander, 2012) foregrounds the understanding and appreciation of the therapeutic aspects of dance and movement as mechanisms through which victims and survivors of crimes such as sexual abuse in childhood or rape in war experience, sediment and access these traumas in and through the body, to enable victims to seek justice and promote healing and reconciliation in damaged lives and communities. It is argued that such emerging research is crucial to developing practical and humane alternative modalities of testimony and witness conventionally sutured to verbal language (see Heydon and Powell, 2016), as well as informing legal, therapeutic and restorative justice regimes and public knowledges of crime in more humane somatic forums, all important issues for criminology and the criminal justice system.

\section{Trauma and the language of dance}

For victims/survivors of sex crime, dance and movement studies offer the possibility of developing modes of expression and articulation that minimise secondary trauma that can ensue by the requirement to verbalise trauma in the spoken word, and open further pathways to expressive catharsis, personal transformation and recovery, for individual victims and 
damaged communities (Lebaron et al, 2013). For child victims who do not possess the cognitive understanding of (adult) sexuality or the mature brain function necessary to process such trauma at the time in order to voice it and seek help, such somatic and corporeal based techniques offer potentially valuable and empathic routes for the communication, prevention, and also broader public understanding of this form of trauma that exceeds and frustrates, and can also be increased and menaced by, 'rational' verbal language (see Millet, 1989). As dance and movement scholarship attests, these developing methodologies focusing on the moving body and how its cultural and symbolic meanings can be used to analyse kinaesthetic and choreographic representations and performances of such moving 'texts' of suffering in order to enhance and inform public knowledges and awareness of these crimes and their manifold harms. These observations and findings present strong challenges to existing legal, judicial and policing methodologies and practices that rely heavily_-if not entirely—on the production and capture of verbal or spoken testimonies of witness and their contestation by their lack of conformity to relatively static or hegemonic logical structures of adversarial legal-rational discourse. Victim/survivor bodily experiences are also subject to reification into narrowly rationalised representations of bodies in movement and pain, for example empirically observable biological forensic evidence of the bodily ephemera of sexual violence, such as physical injuries, bio-chemical traces or other evidence of contact or penetration. Audience responses to choreographies of conflict and the aggressive/defensive/adversarial crime narratives attached to them are open to a number of challenges and interpretations, what audiences believe and accept as credible or reject as exceeding the bounds of credibility - despite different rationalisations of the 'true' meaning behind the choreographed movements, as opposed to the narrative rationales behind them-is another matter, as observed in the controversy over the dance in 'Elastic Heart'.

While dance and movement studies can help us to gain a fuller and more nuanced comprehension of the distinctiveness of these texts and their meanings, it is important not to overstate or reify these dichotomies into another version of the familiar mind/body split. Language and dance are both different and entwined. As Adshead (1986a: 2) states, the 'language of dance' is a commonly used and seemingly harmless and straightforward phrase but can carry the dangerous assumption that language and the arts 'mean' in the same ways, they patently do not. However, as she also notes, at the same time the meanings of dance, like all art forms and works, are not universal or anomalous, all movements and indeed the body are deeply culturally encoded and shaped by their social contexts with respect to meaning and reception. These distinctions and ambiguities are complicated but not impossible to decipher; sensitivity to these phenomena offered by the integration of dance and movement studies into any such analysis presents a potential aid to perception and understanding, offering new apertures for insight, knowledge, expression and question formation. While a dance work might be obviously about something in its explicitly narrative sense, its deeper or other meanings may be harder to conceive or enunciate; the introduction of a narrative thread, something the audience already 'knows', when presented choreographically can unseat previous certainties and invite audiences to ponder, '...not simply accepting the work as a given by working at it to find several, possibly conflicting, interpretations' (Adshead, 1986b: 22). Indeed, many legal practitioners, and criminals, will not find this process or logic 
completely unfamiliar, though the meanings, audiences and contexts may be entirely different. These meanings, mined from such alterative cultural forums, do indeed work to shape law as well as notions of crime and justice, as reciprocal ideologies of normality, deviance and regulation inform and inspire artistic creativity, agency and enterprise (Cropley et al, 2008). As art and law are hence intricately if not obviously entwined, so are dance and crime, and hence so too should be their modes of theory and analysis. In their own ways, both art and law aim to get at the 'truth', while art and crime aim to unseat, exploit, ridicule or change it, albeit not always the same truths or in the same manner.

\section{Childhood sexual abuse, popular culture and dance}

'Problems' of memory and its transmission via 'credible' testimony that reaches a certain level of coherence have dogged the investigation, prosecution and prevention of long term, widespread and/or historical sexual abuse of many and varied vulnerable victims for a long time (see for example the recent statement by Sir Bernard Hogan-Howe below). Against this backdrop, popular culture forms like music videos have colonised the vacant space of public and private discourses around sexuality, violence, intimacy, embodiment and abuse. It has been argued that this is the not always intentional result of moral campaigns aimed at protecting the 'innocence' of childhood, thereby often leaving children and adult victims of child sex abuse ignorant, confused, bereft, and abject (Orbach, 2009; Millet, 1989, Kristeva, 1982) — with little or no language available to 'speak' the crimes committed against them, let alone public forums through which this speech can be heard. These problems have obstructed access to justice for victims of these crimes for generations, if not centuries, confounding victims' ability to report abuse and thereby allowing offenders to avoid public censure and punishment and deny the damage that they cause. This edifice of silence, ignorance and secrecy have actively contributed to the proliferation child sexual abuse, obscuring the problem, glossing the harm caused, even denying its existence in public and private consciousness, making it less likely for victims to seek or get help, and protecting and emboldening perpetrators to continue their offending behaviour as a result of this de facto neutralisation built into existing social institutional structures. This leaves victims open to further victimisation and exploitation by a social order that not only enables and derides but moreover capitalises on the commodified sexualisation of children and childhood through a widespread cultural politics of denial (Cohen, 2000; Calderone, 1989; Orbach, 2009).

Current controversies regarding policing and prosecution of what have been termed historical child sex abuse cases give rise to many concerns and aporia with respect to competing and partial — in both senses of the word-discourses of these crimes and how they are represented, perceived and understood in a variety of cultural forums, by victims, offenders, law enforcement, and other audiences. These are, by their nature, messy crimes, often eliding dualistic models of victim/perpetrator even as they elicit high levels of moral opprobrium, public outrage and disgust, if not outright 'moral panic'. Recent remarks by the Metropolitan Police Commissioner Sir Bernard Hogan-Howe regarding the challenges of determining 'the truth' and who to believe in assessing allegations of sexual abuse in childhood underscore the difficulties of, in his word, 'neutralising' the shifting dynamics, contradictions and ambiguities of memory and experience in the investigation of (historical) claims of childhood 
sexual abuse (BBC, 2016). Yet it is this very process of neutralisation, or the search for certainty through a discourse of static rationality, or the security of certainty that Adorno so consummately critiqued, that can contribute to the lack of clarity regarding the lived realities of child sex abuse and potentially obscure or pervert, rather than expose, the real truth. At the same time, controversies over what the truth about the sexual abuse of children actually is, how it happens, where and by whom, who these children and their abusers are, etc, are readily reproduced within popular cultural representations of these crimes in fictional crime drama and other 'true crime' genres in ways that are often clichéd, stereotyped and highly deceiving (see Selzer, 2007). On the other hand, occasionally such representations emerge into the public domain via choreographic or other artistic performances that elicit public recognition among some audiences, some of whom have their own memories of sexual abuse in childhood 'triggered'.

A diversity of research on violent/sexual abuse shows that it is these very lived, corporeal and emotional ambiguities and complexities surrounding the relationships between victims and abusers in their everyday physical interactions that shape, and sometimes distort, memory and understanding of what has taken or is taking place. These fundamental yet difficult 'truths' have serious consequences for the articulation and expression of differing accounts presented in 'factual' 'objective' discourse that conforms to evidential models of credibility and satisfy legal criteria used for assessing and evaluating utility in court, and the prediction of success in terms of resulting in a conviction — and indeed for the representation of these narratives in popular cultural genres, such as music videos like Sia's 'Elastic Heart' (2015). These processes of articulation and meaning are particularly fraught for victims, and for those tasked to assess, capture and assess the value of these testimonies. Psychological studies have shown that memory impairment with respect to experiences of childhood physical and sexual abuse are affected by the relationship of the perpetrator to the victim, with abuse carried out by a caregiver linked to less persistent memories by victims (Freyd et al, 2001). Similarly, both victim and perpetrator accounts of 'transgression' within what are broadly termed 'romantic' relationships lack the 'self-serving biases' present in accounts of transgression in non-romantic relationships whereby perpetrators tend to downplay the damage caused by their actions and victims tend to 'exaggerate' it; neither tended to display this disparity in romantic or erotically charged relationships (Kearns and Fincham, 2005). Additionally, in Baumeister et al's (1990) study of autobiographical accounts of violent interpersonal conflict by victims and perpetrators, narratives by perpetrators (those who angered) tended to be presented as meaningful, comprehensible, isolated and closed, with no long term negative effects; whereas the victim narratives (those who were angered) tended to perceive such incidents as open ended and continuous associated with long term and ongoing trauma, and that their anger is the result of an accumulated series of provocations extending beyond the event itself, signalling significant and long term differences between perpetrator and victim experiences and accounts of anger and sexual betrayal and/or violent/sexual abuse. In recent critical criminological research, attention is drawn to the fraught and complex confluence of intimacy, sexuality, embodiment, technology, incest law and popular culture and their effects on what are considered appropriate boundaries regarding expressions of desire in what Karaian (2016) terms 'relative lust' and 'accidental incest'. Elements of these phenomena are 
recognisable in some of the movement dynamics, interactions and emotional responses of the dancers in 'Elastic Heart'. Perhaps it is these very uncertainties and ambiguities with respect to performances of anger, aggression, pain, trauma and love expressed choreographically that has touched a nerve or 'triggered' somatic memories of child sex abuse among viewers. This in itself tells us something about the nature of incest and child sex abuse that has been recorded in scholarly research on the subject and is well known among experts, as previously indicated, but is less well publicised in popular cultural forms, and is not characteristic of how such sensitive issues are narratively construct in popular media forms such as true crime or crime fiction (e.g. Selzer, 2007).

Even within accounts of such anger and betrayal in pop music/video culture, the act of interpretation and the determination of meaning can be difficult to decipher and make sense of, such as in other recent high profile examples of performances of angry and/or 'crazy' femininities in apparent response to male betrayal and/or deceit. Notable and controversial recent examples include failures to adequately, convincingly or consistently perform 'perfect' celebrity femininities in the wake of apparent male deception, betrayal and/or abuse, by artists such as Lauryn Hill (Bruce, 2012), in video/music performances by Beyoncé in her 'visual album' Lemonade (2016), and Beyoncé's sister Solange Knowles in the now infamous TMZ video in which she apparently attacks her brother-in-law Jay Z while Beyoncé observes dispassionately from the side (TMZ, undated). What erupts into the public sphere is that even the most aspirational, idealised and apparently perfect women, relationships and families have their problems, and those who are marketed as iconic or 'perfect' celebrity women also have feelings of jealousy, insecurity, envy, 'craziness' and rage. The representation in the popular music video genre of an enraged and 'crazed' girl in such a highly charged encounter with an older man is much less common, but when a child, a real child, is invoked in this context, the determination of agency, sexuality, rationality and desire are can be even more fluid and complicated, and anxious. At the same time, cultural attitudes with respect to what audience projections or assumptions about what lies behind the emotions and interactions between two such emotionally charged and moving 'naked' bodies, in an exposed but quasiprivate space, and what is really going on in terms of power agency and responsibility as presented in 'Elastic Heart' is currently in a acutely transitional process. Compared to just a decade ago or more, who was believed in relating such encounters in public was relatively easy to predict-i.e. not the child (Millet, 1989; Calderone, 1989), though these historical (un)certainties are eroding, not least due to the emergence of these previously hidden or silenced experiences into the public realm, in this instance, as encountered and responded to by audiences in the language of dance.

Drawing upon Kristeva (1982), such crises and controversies occasioned by the 'triggering' of traumatic memories of 'unacknowledged suffering' such as of child sex abuse by dance performances in videos like 'Elastic Heart' emerge as a result of deep collective and individual abjection, and this itself is a sign of the failure of symbolic or institutional language to discern or acknowledge the full spectrum of experience elicited by such trauma. What is needed in such critical circumstances, she argues, is a return to the private/subjective/feminine/maternal semiotic language of pre-Oedipal experience, to refresh 
and reconnect the meaning of public/institutional/masculine/paternal symbolic language to the lived and embodied experiences of real people whose voices and experiences of trauma and abuse have not yet been articulated or heard. This can happen through the strenuous process of expression in semiotic languages that are formative in nature and lacking in logocentric rationality, or it can be articulated more clearly in other 'alternative' discursive forms, most notably in art. While Kristeva was most interested in poetic writing, her thesis can also be extended to the other arts, including dance, and the analysis of such artistic expression can reveal deep truths about the pain and trauma experienced, especially by those whose suffering has not been acknowledged or addressed (Kristeva, 1982; Beardsworth, 2004; Grosz, 1991).

The messy, formative and/or 'irrational' character of these articulations of trauma and suffering in art understandably elicits concern and suspicion on the part of legal, judicial and criminological agents, but to consider these articulations anathema to the agencies tasked with prevention of child sex abuse and justice for victims would be to contribute to their suffering and abuse and enable perpetrators to continue their crimes unabated. Dance, and dance and movement studies, as well as poststructuralist theory with they draw upon, are open to, tolerant of, and cognisant of the sedimentation in the body and polymorphous kinaesthetic meanings of such painful experiences. Analyses based on these theories can potentially aid, rather than frustrate, criminological inquiry by helping to elicit meaning from such non-verbal and performative data and/or audience responses to them, sometimes as represented in the mass media. Such controversies involving 'kinaesthetics and proxemics' by their novelty can (momentarily?) elide hegemonic systems and (phal)logocentric discourses that silence these testimonies, generating significant challenges to existing 'systems of signification'. Though elusive and fleeting, these moments constitute occasions of immense potential:

Tolerance of ambiguity and acceptance of diversity in interpretation in the arts is not necessarily the weakness that it is sometimes assumed to be-in post-structuralist thinking it is unavoidable - and in consequence these two positions are often in conflict...The notions of 'systems of signification' have become commonplace, there has been less attention paid to kinesics and proxemics which, it might be thought, would have more relevance to dance and would bring the non-verbal levels of communication into sharper relief (Adshead-Lansdale, 1999:6).

The alternatives of opening legal-judicial and protective systems to these sorts of popular and semiotic articulations is the challenge. Perceiving this dance and audience responses to it as merely part of the superficial background 'noise' of pop music culture, or that dance and movement do not fit existing systems of signification and are thus meaningless, and simply ignoring the memories of what has been 'triggered' in audience responses to 'Elastic Heart' would be to deny the veracity and urgency of the unacknowledged suffering that has been serendipitously exposed by this choreographic work of art. With the arising of survivor/victim groups and individual testimonies via social media, there is reason to believe that audiences today are less disposed to withdraw back into quiet obscurity in the face of such practiced, wilful indifference or ignorance on the part of criminal justice agencies. At 
the same time, shame, and the relentless speed and disposability of mass popular cultural forms are still salient factors that mean such opportunities for social change and transformation can easily be missed.

\section{Conclusion}

What many victims, and also perpetrators, of child sexual abuse know only too well is that existing institutional systems of child protection are not fit for purpose. In her introduction to the Independent Inquiry Into Child Sex Abuse (2015), the then Chair Hon. Dame Lowell Goddard outlined the following litany of systematic failures to deal with the sexual abuse of children across the board and the subsequent and urgent need to listen to victims and survivors to repair them:

...failures by local authorities; failures in the areas of criminal justice and law enforcement; in education and religion; in national and private service organisations; and in relation to alleged abuse by persons of public prominence. I am confident that this broad range of investigations will give a voice to victims and survivors who have experienced abuse in a variety of institutional settings or where there may have been institutional failings; and will combine consideration of non-recent allegations of abuse with urgent, contemporary issues of child protection (IICSA, 2015: 1)

The emotions and memories 'triggered' by Elastic Heart are hence not (or are not entirely) part of a carnivalesque vortex of postmodern relativism in which victims' and perpetrators' stories and experiences carry the same weight in terms of credibility and urgency, or none at all. This is where dance and movement studies can help. Without being flippant, to quote Shakira (2005), 'hips don't lie'; the language of the (child's/female's) body is truthful, dangerous, and undeniable, even as the conventional assignment of 'unbalanced' states of mind to 'abnormal' female bodies in response to their 'bodily eruptions' is established and persistent:

...[T]he representation/reality, cultural/nature, mind/body associations of speech/movement are also to be found lurking in the background of theories that seek to call into question the Cartesian mind/body dualism and reinstate the power of the body into the cultural frame. For example, they are inherent in Rodolf Laban's (1971) theories of movement in Louis Horst's idea that 'the body is the most dangerous of instruments' (Lloyd, 1968: 92), and in Martha Graham's famous statement that 'movement is the one speech that cannot lie' (Graham, 1968b: 99). Sigmund Freud (Freud and Bruer, 1974) also considered that the 'abnormal' bodily attitudes and bodily eruptions of his (predominantly female) patients were related to their unbalanced state of mind (Thomas, 1995: 7).

For criminology, this is cultural, social, and political ideology that aligns the body with femininities embedded in dance carries with it the potential to either reinforce and reify the suffering of the victims of child sex abuse, or to help elucidate and hopefully remedy what remains a stubbornly recalcitrant arena of the study and understanding of (child) sexual abuse and victimisation. Dance and movement studies as an addition to the armoury of cultural 
criminology offers insights into bodily activity and choreographies of crime that are 'empirical', in the meaning of capturable by sense-based observation, in a new way that is not dependent upon the (phal)logocentric Enlightenment discourses of science, reason and technology, but rather concentrating on its broader semiotic cultural and social constructions and meanings (Thomas, 1995) that also take into account the forensics of bodily and somatic memory. It is the faith in the former that keep obscuring and marginalising the latter, not least in a hard science leaning discipline like criminology. Analysis of specific dance performances and their receptions by audiences, such as those considered here, can also open up and develop the analytic capacity of feminist/criminological critiques that have conventionally been accorded the domain of women's (and girls') experiences and the body, introducing opportunities for new insights and also challenges to previous thinking and possible arenas for the articulation of victims suffering and abuse. Discourses that prioritise rather than deny the experiences of the living, moving, somatic body in relationship are needed in dealing with the lived experiential realities and consequences of child sexual abuse (Salter, 2013).

References:

Adshead, Janet (1986a) 'The Study of Dance Conference Series: Introduction'. In Adshead, Janet (ed) (1986) Choreography: Principles \& Practice. Proceedings of Study of Dance Conference 4. University of Surrey, 4 - 7 April, 1986. Published for the Dance Research Unit by the National Resource Centre for Dance, University of Surrey: Guildford, Surrey. Pages 110.

Adshead, Janet (1986b) 'Issues in the Principles and Practice of Choreography'. In Adshead, Janet (ed) (1986) Choreography: Principles \& Practice. Proceedings of Study of Dance Conference 4. University of Surrey, 4 - 7 April, 1986. Published for the Dance Research Unit by the National Resource Centre for Dance, University of Surrey: Guildford, Surrey. Pages 11-27.

Adshead, Janet (1988) Dance Analysis: Theory and Practice. London: Dance Books.

Adshead-Lansdale, Janet (1999) (ed) Dancing Texts: Intertextuality in Interpretation. London: Dance Books.

Armstrong, Sarah (2015) 'The Cell and the Corridor: imprisonment as waiting, and waiting as mobile'. Time and Society. Pages 1-22.

Baumeister, R.F., Stillwell, A., and Wotman, S.R. (1990) 'Victim and Perpetrator Accounts of Interpersonal Conflict: autobiographical narratives about anger'. Journal of Personality and Social Psychology. November 1990. Volume 59(5). Pages 994-1005.

BBC (2016) 'Police "should be neutral" in sex abuse inquiries'. 11 February 2016. Available online at http://www.bbc.co.uk/news/uk-35546690 [accessed 12/02/2016].

Beardsworth, Sara (2004) Julia Kristeva: Psychoanalysis and Modernity. Albany, New York: SUNY Press. 
Beausoleil, Emily and LeBaron, Michelle (2013) 'What Moves Us: Dance and Neuroscience Implications for Conflict Approaches'. Conflict Resolution Quarterly.

Beyoncé (2016) Lemonade. Parkwood Entertainment, Columbia Records.

Breed, Ananda (2014) Performing the Nation: Genocide, Justice, Reconciliation.

Chicago: Seagull Books.

Bresnahan, Aili (2015) 'The Philosophy of Dance'. Stanford Encyclopedia of Philosophy. Available online at http://plato.stanford.edu/entries/dance/ [accessed 22/04/2016].

Bruce, La Marr Jurelle (2012) “’The People Inside My Head, Too”: Madness, Black Womanhood, and the Radical Performance of Lauryn Hill'. African American Review. Volume 45, number 3. Fall 2012. Pages 371-389.

Calderone, Mary S. (1989) 'Above and Beyond Politics: The Sexual Socialization of Children'. In Vance, Carole S. (ed) (1989) Pleasure and Danger: Exploring Female Sexuality. London: Pandora. Pages 131-137.

Campbell, Elaine (2016) 'Policing and its Spatial Imaginaries'. Journal of Theoretical and Philosophical Criminology. Volume 8, number 2. Pages 71-89.

Campbell, Elaine (2012) 'Landscapes of Performance: Stalking as Choreography'. Environment and Planning D: Society and Space. Volume 30, number 3. Pages 400-417.

Cohen, Stan (2000) States of Denial: Knowing About Atrocities and Suffering. Cambridge: Polity Press.

Copley, Jessica (2010) 'Modes of Representing the Holocaust: A Discussion of the Use of Animation in Art Spiegelman's Maus and Orly Yadin and Sylvie Bringa's Silence'. Opticon 1826. Issue 9. Autumn 2010. Available online at http://www.ucl.ac.uk/opticon1826/archive/issue9/articles/A_H_Copley.pdf [accessed 07/04/2016].

Cropley, D.H., Cropley, A.J., Kaufman, J.C., Runco, M.A. (eds) (2008) The Dark Side of Creativity. Cambridge: Cambridge University Press.

Cvejic, Bojana (2015) Choregraphing Problems: Expressive Concepts in Contemporary Dance and Performance. Basingstoke: Palgrave Macmillan.

Danceon (2015) 'The Story Behind Sia’s Elastic Heart Music Video!’. Director: Erik Anders Lang. Available online at https://www.youtube.com/watch?v=iVJtWWH2qWk [accessed 16/01/2017].

Author, Melissa (2018) "I anticipated some “pedophilia!!!”: (Re)-Constructing the 'Violent Perpetrating Self 'in contemporary child sex crime as "triggered" by dance in Sia's 'Elastic 
Heart'. In Bielby, Clare and Murer, Jeffrey (eds) (2018) Perpetrating Selves: Doing Violence, Performing Identity. London: Palgrave Macmillan.

Durkheim, Emile (2008) The Elementary Forms of Religious Life. Oxford: Oxford University Press.

Elias, Norbert (2000) The Civilizing Process: Sociogenetic and Psychogenetic Investigations. Trans. Edmund Jepbcott. Oxford: Blackwell Publishers.

Ferrell, J. Hayward, K., Morrison, W., Presdee, M. (eds) (2004) Cultural Criminology Unleashed. London: The Glass House Press.

Ferrell, J., Hayward, K. and Young, J. (2015) Cultural Criminology. London: Sage Publications.

Ferrell, J., Hayward, K. and Young, J. (2008) Cultural Criminology: An Invitation. London: Sage Publications.

Ferrell, Jeff and Sanders, Clifford R. (1995) Cultural Criminology. Lebanon, New Hampshire: Northeastern University Press.

Fraleigh, Sondra Horton (1999) Dancing Into Darkness: Butoh, Zen and Japan. Pittsburgh: University of Pittsburgh Press.

Freyd, Jennifer J.; DePrince, Anne P.; Zurbriggen, Eileen L. (2001) 'Self-Reported Memory for Abuse Depends Upon Victim-Perpetrator Relationship'. Journal of Trauma and Dissociation. Volume 2(3). Pages 5-15.

Fuhler, Sia (2015) 'Elastic Heart' [official music video]. Available at https://www.youtube.com/watch?v=KWZGAExj-es [accessed 07/04/2016].

Gerth, H.H. and Mills, C. Wright (eds) (2009) From Max Weber: Essays in Sociology. New York and Abington: Routledge.

Good, Jenna (2015) "'I can cry watching a kid do that kind of choreography": Sia talks about controversial Elastic Heart music video which includes Maddie Ziegler, 12, and actor Shia LeBoeuf'. The Daily Mail Australia and The Mail Online. Available online a http://www.dailymail.co.uk/tvshowbiz/article-2916310/I-cry-watching-kid-doing-kindchoreography-Sia-talks-controversial-music-video-Elastic-Heart-includes-Maddie-Ziegler12-actor-Shia-LaBeouf.html [accessed 1404/2016].

Grosz, Elizabeth (1991) Sexual Subversions: Three French Feminists. Crows Nest, NSW: Allen \& Unwin.

Grow, Kory (2015) 'Sia Apologies for Controverial "Elastic Heart" Video with Shia LeBoeuf'. Rolling Stone. January 8, 2015. Available online at http://www.rollingstone.com/music/news/sia-apologizes-for-controversial-elastic-heartvideo-with-shia-labeouf-20150108 [accessed 1404/216]. 
Hammond, Philip E. and Hammond,Sandra N. (2009) 'The Internal Logic of Dance: A Weberian Perspective on the History of Ballet'. Journal of Social History. June 1979. Volume 12, issue 4. Available online at http://www.jstor.org/stable/3787367?seq=1\#page_scan_tab_contents [accessed 11/02/2016].

Harding, James Martin (1997) Adorno and 'A Writing of the Ruins': Essays on Modern Aesthetics and Anglo-American Literature and Culture. New York: SUNY Press.

Hayward, Keith (2012) 'Markets, Consumption and Crime: Consumer Culture and the Urban Experience'. In Ferrell, Jeff and Hayward, Keith (eds) (2011) Cultural Criminology: Theories of Crime. Aldershot: Ashgate Publishing.

Heydon, G. and Powell, A. (2016) 'Written-Response Interview Protocols: an innovative approach to confidential reporting and victim interviewing in sexual assault investigations'. Policing and Society: An International Journal of Research and Policy. Pages 1-16.

IICSA [Independent Inquiry into Child Sex Abuse] (2015) 'Statement By the Chair of the Independent Inquiry Into Child Sex Abuse'. available online at https://www.iicsa.org.uk/sites/default/files/update-statement-november-2015_0.pdf [accessed 26/04/2016].

Jackson, Naomi, and Shapiro-Phim, Tony (eds) Dance, Human Rights and Social Justice: Dignity in Motion. New York and Plymouth: Scarecrow Press.

Jansohn, C., Ulges, A., Breuel, T.M. (2009) 'Detecting Pornographic Video Content by Combining Image Features with Motion Information'. In MM '09 Proceedings of $17^{\text {th }}$ ACM International Conference on Multimedia. New York. Pages 601-604.

Karaian, Lara (2016) 'Relative Lust: accidental incest's affective and legal resonances'. Law, Culture and the Humanities. Pages 1-20.

Kearns, J.N. and Fincham, F.D. (2005) 'Victim and Perpetrator Accounts of Interpersonal Transgressions: self-serving or relationship-serving biases?'. Personality and Social Psychology Bulletin. March 2005. Volume 31(3). Pages 321-333.

Kristeva, Julia (1982) The Powers of Horror: An Essay on Abjection. New York: Columbia University Press.

LeBaron, Michelle; MacLeod, Carrie; Acland, Andrew Floyer (eds) (2013) The Choreography of Resolution: Conflict, Movement and Neuroscience. Chicago: ABA American Bar Association Publishing.

LeBaron, Michelle and Alexander, Nadja (2012) 'Dancing to the Rhythm of the Role-Play: Applying Dance Intelligence to Conflict Resolution'. Hamline Journal of Public Law \& Policy. Volume 33, issue 2. pages 327-362.

Leszkiewicz, Anna (2016) 'From Serial to Making a Murderer: Can True Crime as Entertainment Ever Be Ethical?’. 15 January 2016. New Statesman. Available online at 
http://www.newstatesman.com/culture/tv-radio/2016/01/serial-making-murderer-can-truecrime-entertainment-ever-be-ethical [accessed 15/07/2016].

Leithart, Peter J. (2011) 'The Civilizing Process' [review]. The Credenda Agenda. Available online at http://www.credenda.org/index.php/Reviews/the-civilizing-process.html [accessed 29/02/2016].

Martin, Randy (1998) Critical Moves: Dance Studies in Theory and Politics. Durham and London: Duke University Press.

Millet, Kate (1989) 'Beyond Politics? Children and Sexuality'. In Vance, Carole S. (ed) (1989) Pleasure and Danger: Exploring Female Sexuality. London: Pandora. Pages 217-224.

Monasterio, Lucia Ortiz (2015) 'Wonderful Advice From Socrates and Nietzsche:

Dance...Dance Alone’. Available online at http://www.faena.com/aleph/articles/wonderfuladvice-from-socrates-and-nietzsche-dance-dance-alone/ [accessed 16/01/2017].

Nietzsche, Friedrich (1969) Thus Spoke Zarathustra: A Book for Everyone and No One. Translated by R.J. Hollingdale. Harmondsworth: Penguin.

Orbach, Susie (2009) Bodies. London: Profile Books.

Presdee, Mike (2000) Cultural Criminology and the Carnival of Crime. London: Routledge.

Riff, David (2015) 'Was Marx a Dancer?' Eflux. Availabe at http://www.eflux.com/journal/was-marx-a-dancer/ [accessed 11/02/2016].

Salter, Michael (2013) 'Grace's story : prolonged incestuous abuse from childhood into adulthood'. Violence Against Women. Feb 19(2):146-65.

Selzer, Mark (2007) True Crime: Observations on Violence and Modernity. New York: Routledge.

Smith, Dame Janet (2016) The Dame Janet Smith Review Report: An Independent Report into the BBC's Culture and Practices During the Jimmy Savile and Stuart Hall Years. Published 25 February 2016. Available online at http://downloads.bbci.co.uk/bbctrust/assets/files/pdf/our_work/dame_janet_smith_review/con clusions_summaries.pdf [accessed 22/04/2016].

Spencer, Dale C. (2010) 'Cultural Criminology: An Invitation to...What?’. Critical Criminology. September 2011. Volume 19, issue 3. Pages 197-212.

Thomas, Helen (1995) Dance, Modernity and Culture: Explorations in the Sociology of Dance. London: Routledge.

TMZ (undated) 'Jay Z Physically Attacked by Beyonce's Sister Solange'. Available online at http://www.tmz.com/videos/0_6lrpg6kh/ [accessed 17/01/2017]. 
Vernallis, Carol (2004) Experiencing Music Video: Aesthetics and Cultural Context. New York: Columbia University Press.

Weber, Max (2011) The Protestant Ethic and the Spirit of Capitalism. Translated by Talcott Parsons. London: Unwin Paperbacks. 